\title{
Analysis on the Application of Invisible Class in Art Curriculum from the Perspective of New Media
}

\author{
Fang Han \\ College of Fine Arts \\ Hainan Normal University \\ Haikou, China 571100
}

\begin{abstract}
Today, people live in an era with instantaneous changes. The rapid speed and wide range of changes has made our life highly unstable. In addition, the network in community and school has initiated a reform in education content and method. Since the $1960 \mathrm{~s}$, the characteristics of digitization and intelligence in learning, education and classroom teaching are increasingly obvious with the arrival of the era of knowledge economy and information under the influence of technology progress. The blackboard, chalk and blackboard eraser are not the only tools of teachers, and the teaching equipped with computer and multimedia audio-visual equipment has become the standard of classroom teaching. For instance, mobile learning, cloud library, MOOC, flipped classroom and maker education. The concept of "Internet plus" presented by school education enjoys popular support, such as 3D printing technology, somatosensory interaction technology, virtual world (VR) and augmented reality (AR) technology. There are too many technologies that can be integrated in school education. Our students live in the social and cultural "ecosystem" formed by Google, Baidu, MicroBlog, WeChat, ipad, iphone and other media and technologies. With respect to the "young people in the digital age", we should think about some problems seriously: How to integrate information technology into the teaching of fine arts sufficiently and reasonably? How to eliminate or reduce the bad influence of "invisible class"? How to avoid "flavor reversion" in the teaching of fine arts?
\end{abstract}

Keywords-literacy; new media; invisible class; critical thinking; curriculum resource development

\section{INTRODUCTION}

In 2001, China officially started the reform of basic education curriculum. As an indispensable part of the reform, the art discipline and other disciplines are trying to walk a way of teaching reform with the disciplinary characteristics under the guidance of the overall concept and ideas of the education curriculum reform in China; The United States has added "art and design" on the basis of the STEM (science, technology, engineering and mathematics) model, forming the STEAM model. Undoubtedly, the "illiteracy" in the future society is no longer a lack of knowledge, but a loss of learning ability. Under the impetus of educational reform, contemporary society should tend to be the product of web culture and media culture. The intuition, accuracy, quality and technicality of materials in art education and the scenario, specific place, systematic curriculum, staged nature of teaching implementation and other features aim to cultivate students' critical thinking and aesthetic way and are restarting from a new starting line.

\section{SIGNIFICANCE OF CONSTRUCTION OF INVISIBLE} Class FOR ART TEACHING FROM THE PERSPECTIVE OF NEW MEDIA

New media is generated with digital technology. Nowadays, it is very easy for the teenagers to use various APPs on the mobile phone and Internet. Its verified communication forms and penetrability unparalleled by traditional media has become an efficient instrument for global communication. The China New Media Development Report (2011) points out that, China is already the country with the most new media users. As of the end of 2010, the Internet users in China have reached 457,000,000 and mobile phone users have been more than $800,000,000$ and reached $890,000,000$ by the end of March 2011. Zhang Junhui: Influence of New Media on Teenagers' Growth and Backward Educational Countermeasures. The teenagers' views of world, life and value are still in the stage of formation. Their cognition ability towards new media is unequal to their ability of using it, and such situation has become one of the main factors influencing their healthy growth. Teaching art from the perspective of new media is one the "invisible classes" of modern art teaching. We should think how to integrate the network media favored by them into the classroom teaching, improve their interest in learning, and cultivate them to select the information for improving their literacy with critical vision and esthetic thinking. Facing the challenges and opportunities brought by this media reform, we should make reasonable use of advantages of new media, to give full play to its strong points, which is of practical significance for promoting the formation of students' independent innovative spirit and the expansion of practice ability on their own. Logic inference and theoretical explanation still have the influence not to be neglected in the art history development. With respect to the study of art appreciation in the curriculum, teachers often choose the traditional teaching method, which are bold and unrestrained with intense rhythm, depressing and boring atmosphere. Facing the above difficulties, in order to complete the classroom teaching timely and effectively, respect students' position of subject, inspire their 
independent consciousness and form the good teacherstudent relation, the teachers must seek the possibility for invisible class implementation. In the art appreciation series of Art Curriculum Standard of Senior High School (Version 2011), the viewpoint that students should understand the vision contained in images continuously has relieved the realistic demand of teaching and learning conflict, and cultivated students' media literacy education. The deduction of art history mode since the times of Hegel: Historians have different opinions for one same art works under a magnificent awareness and narrative structure. Therefore, the methods of art appreciation can still present the diversity and uniqueness. The ways of critical thought will formed as students appreciate from different perspectives, thus their independent exploration awareness is aroused. And they can communicate with teacher with equal position, so the excellent teacher-student interactive win-win situation is formed. The Opinion printed and published by General Office of the CPC Central Committee and General Office of the State Council points out that the key abilities mainly include cognitive ability, cooperative ability, innovative ability and professional ability. According the author, these four key abilities will ultimately focus on settlement of problems. Under the network platform constructed by new media, teachers play a role of guidance in the classroom and cultivate their ability of solving problems.

What are the conflicts between formal class and "invisible class"? Formal class refers to the regular teaching with clear cognition target and emotional objective. "Invisible class" means the unspecified regulation, value and belief conveyed to students through deep structure of the meaning and the social relation of activities in the school and classroom. In short, the art construction, art classroom, culture corner, art feeling, and the sense of atmosphere are the invisible class. If you can feel the profound national culture, campus culture, atmosphere of study when you enter into a school, then children who study in such environment will have totally different status. Until recently, some educators start to propose that it is necessary to conduct a thorough research on the relations among ideology, teaching and curriculum. The ideology is reflected in the foundational views those are arranged, guided by educators themselves who give the meanings. Art is originated from life yet it is higher than life. In the classroom, students' definitions of art are as the following: (1) art is bound to be created by human; (2) art must be made into art on purpose. At present, the multimedia technology is a kind of invisible classes. The multimedia development is influencing students' physical and mental development and value orientation subtly. We should integrate the development prospect and information technology into the art education, so that students may recognize and percept art with critical thinking. Just as what Teacher Duan Peng mentioned in the interview with Wang Haiqian: "Suggestions for Implementing the Curriculum in Local Places and Schools" of Art Curriculum Standard of Senior High School (Version 2017) point out we should "use information resources sufficiently and rationally". This has conveyed us two pieces of information: First, it should be "sufficient". Students are no longer relying on traditional teaching, textbooks and content written by teacher on the blackboard for acquiring knowledge, but they can get materials for study from the Internet and acquire direct feeling of study contents from multimedia resources including films televisions, thus to study on their own using computer and Internet. Second, it should be "rational". Not all the "modern" things are "good". In the real circumstances, it is common that teachers use the multimedia equipment as "a kind of show". Teacher Duan Peng also mentioned that: "in order to show a sense of "modern" in teaching, teachers often use micro-video, ipad and other displays. In the end, teachers are in tearing hurry and students are unable to accept all the contents. The "flavor" of art class is reduced or even gone". "Flavor reversion" of teaching indicates that it is merely a formality, losing the essence of aesthetic art and experience.

The modern education stresses to cultivate students' critical thinking generally. Teacher Duan Peng points out that teaching via informationization is a good environment for cultivation of students' such thinking ability. Teachers should give more open and free space to students, to help them to get free ideology and independent spirit. This is a supreme pursuit for education. Its ultimate stress is laid on "thinking" and "character", which also conforms to the basic thought of literacy standard teaching. We should keep "core literacy" in mind at all times. In the argument of Deriben, the norms acquired by students are mentioned, namely, independence, achievement, generous charity, and uniqueness. Deriben, Aronotz and others have helped make clear that, as a socialized institution, school is playing a role in the system network with wider scope. Invisible classes are inclined to be the expression of an ideology, and they constitute students' understanding of the world. In order to make a breakthrough in the "invisible class", educators should help students to understand. Knowledge can change, which relates to people's interests, and it should also be examined according to its effective views. The praises in classroom are closely related to rights. The real meaning of teacher's role lies in the social relationship network and values generated by the authority. Previously, the pursuit of invisible course in learning art is which student has won the prize. Today, however, the invisible courses in primary and secondary schools or the normal colleges prefer to research national culture. The classroom will be arranged by teachers specialized in national culture research, so that it may be of national cultural atmosphere. For instance, hang some paintings of the children in the classroom. The change of classroom arrangement will create a different atmosphere, which is a kind of campus culture and guidance. These do not include the teaching in classroom, but the guidance showed by the teacher in class and the painting being praised in the teacher's potential consciousness. Taking Lesson 5 Dough Molding of Grade Eight (Jiangxi Fine Arts Publishing House) as an example: Lesson period: one period. Textbook analysis: this course is a course in the field of "design and life". "Dough molding" is an art of "cooked wheaten food", which also represents the "cooking culture" in the excellent culture traditions of Chinese nation, and it is inherited and retained as "a special skill in China". Both clay sculpture and dough modeling belong to the molding. By studying this lesson, students not only master the methods of 
molding, realize the joyfulness of molding, but also they are cultivated to seek beauty, discover beauty, feel beauty and carry forward beauty in the daily life, so as to improve their living skills. "What do students learn in school?" Robert Deriben points out against this question that, what the students learn is far beyond those instrumental knowledge and skills. As for the traditional school educational views, "they are the viewpoint about cognition in nature, and can only hold the ground partially." Steven Aarons regards school as "a social environment where children can get more knowledge than the regular classes". "Should school cultivate the young people to adapt the society, or cultivate them to shoulder the mission of reform to improve the society?" The Opinion on Deepening the Educational System and Mechanism Reform printed and published by General Office of the CPC Central Committee and General Office of the State Council points out that, we should pay attention to cultivating the key ability of supporting lifelong development and adapting to the requirements of the times. The cultivation of such key abilities of students should be strengthened in the process of cultivating their basic knowledge and skills. In the contemporary "Internet+" era, the teachers should combine the discipline content with network media literacy education, and combine the unique humanistic spirit in the discipline of art with students' actual life, so as to cultivate students' sense of independent exploration, improve themselves, and strengthen their independent exploration ability, thus to enhance their aesthetic literacy of truth, kindness and beauty.

\section{APPLICATION OF INVISIBLE ClasS UNDER NEW Media Vision to CREATE ART TEACHING CREATIVITY AND CREATIVE ATMOSPHERE}

We always take initiative to make an exploration of an object while we are watching it. Vision is like an intangible "finger". We move in the surrounding space with such intangible finger. We walk far away to the place where various things can be found. We touch them, catch them, have a scan on their surface, seek their boundary and explore their texture. It was mentioned in the education framework of VCAE (Visual Culture Art Education) that, we should attach more importance to the new visual media and other accessible equipment used in teaching and studying. It is very important to understand the visual environment. In the early stage of 21 st century, our culture was constructed vigorously and visualized totally. This has built the environment engineering and analyzed the meaning, and they often talk with others about a certain thing with or without intention, in a sincere or manipulative way. In the "Internet+" era, we should understand the content of communication to live a better life in such environment. Two thousand years ago, some ancient educators in China have already had certain knowledge about the relation between human and environment. Yan Zhitui of North Qi Dynasty once said in the Family Instructions of Master Yan Muxian that, "one is influenced imperceptibly, and the nature is similar to it." It refers to that human's ideology will be influenced subtly, and change accordingly.
Create relaxed classroom atmosphere and strengthen students' creativity. Mo Tzu reached a conclusion from dying silk that, "if we dye the silk in blue, it will become blue; if we dye it in yellow, and it will become yellow. Its color changes with the change of colorant." Education is of certain dominance. In the art education of children, we should make coordination to protect the potential characteristics of children in their growth process in the appropriate dominance, so that they can grow under the guidance of fine arts cultural theme, and conform to and assimilate into a certain behavior affected by their own habitual thinking in the appropriate controlling process guided by the art teacher. In this way, the new thinking status and behavior direction will be generated, and they recognize and start to establish the thinking way of art. Thus, the result of children in studying art is bound to be distinctive, creative, and is the individual expression with the sense of art.

\section{TEACHING STRATEGIES OF INVISIBLE ClASS IN CURriculum RESOURCE DEVELOPMENT FIELD FOR ART TEACHING UNDER NEW MEDIA VISION}

The part of IV - Course Resources Development and Utilization Suggestions in Section IV - Implementation Suggestions of Compulsory Education Art Curriculum Standard (Version 2011) suggests that, the resources of art curriculum mainly include the resources of school, nature, society and network. The development of art curriculum is beneficial to the enriching the art teaching content, improving the effectiveness of art teaching and highlighting the characteristics of local art education.

- Meet the basic conditions for students to study fine arts

- Improve the basic materials and setting for art teaching

- Enrich the resource of books and images for art teaching

- Expand the art teaching resources outside school

- Develop and utilize the art resources on the Internet

- Make full use of natural, social and cultural resources

- Take initiative to develop local resources for art curriculum

In the new curriculum, it is stressed that teachers should make use of the resources outside school, such as art gallery, library, museum, artist studio, art workshop, zoo, botanical garden, park, amusement park, shop, community, village and so on, to carry out diversified art education activities; qualified schools should take initiative to develop the informatization resources for the curriculum, make full use of the Internet, explore the new teaching method, and carry out exchanges between students, schools, provincial, municipal and international students' art works, and art achievements of teachers. In addition, the natural resources (e.g. natural landscape, natural materials etc) and social and cultural resources (e.g. recreation and sports, festivals, commemoration day, achievements in construction, 
significant historical events, legends, stories, film and television, drama, national and folk art as well as cultural relics) may be used for art teaching. Local places are provided with abundant class resources. School in rural area, remote area and areas inhabited by the minority nationalities can act according to local conditions, make full use of local resources, carry out the characteristic art teaching, and they should also take advantage of remote education network, introduce in the high-quality art teaching resources, and improve the effectiveness of art teaching. Suggestions for implementing this Course in Local Places and School in Implementation Suggestion (IV) of Art Curriculum Standard of Senior High School (Version 2017) point out that:

- Understand the importance of developing and utilizing curriculum resources fully

- Improve the environment of software and hardware in schools implementing high school art curriculum

- Make adequate development and full use of social culture and natural resources

- Absorb the excellent traditional cultural resources of various Chinese nations widely

- Use the informatization resources fully and rationally

- Seek and use the generative curriculum resources

It is easy to understand that, the current art curriculum standard encourages to study in the informatization environment, set up the information resources platform relating teaching contents, make full use of resource websites, computer software and application software at end point that are relating to art disciplines, so that students may carry out independent studying and research-related studying better by using high-quality social art teaching resources. Propose the real-time guidance opinions from curriculum management, construction of teacher's team, student development, teaching facilities, teaching quality, evaluation system and curriculum resource development and utilization and other aspects in combination with local reality; local places or schools can compile the local or school art textbooks reflecting the core literacy of art and having distinctive regional characteristics based on the local art teaching resources to satisfy the art studying or vocational development demand of local students or students of this school and meet their multiple choices. As the main part of ordinary high school art course implementation, schools should develop and utilize curriculum resources, promote transformation of art curriculum to specific studying tasks, strengthen the relation between the course and local economic culture, intensify the relation between teaching and actual living circumstances, expand the space of art curriculum, develop students' core literacy of art discipline. And we should create the environment with school's art discipline characteristics and campus cultural characteristics, absorb the excellent cultural spirit and core values, such as pursuing harmony, respecting nature, complying with social morality, advocating unity, honest and amicable, loving life, respecting the aged and taking good care of children, hardworking and thrifty; expand the art curriculum space in terms of content and method, take full advantage of computer, multimedia and Internet technologies, various art application software and other informatization art curriculum resources, and cultivate students' abilities of distinguishing, criticizing, selecting and using of various network art information and relevant information. In the link of seeking and using the generative class resources, school should encourage or request the teachers to seek the problems, events and results generated in the communication and interaction between teacher and student, student and society, student and student, and teachers' teaching cases, teaching reflection and students' growth process, works and repercussions, and sum up, sort out and improve these materials timely, to apply them in the high school art teaching, so as to enrich curriculum and teaching method.

\section{CONCLUSION}

There is no doubt that information technology is the basis for making progress. In the face of the emergence of new media, what teachers confronting with at present is not in technical level but the requirement for understanding what students are doing and what ability students have. At the same time, the individualization of teaching, the separation of effective teaching from ineffective efforts and the "feedback + reflection" cycle determine the future of art course teaching and should get better use of new media to realize it. However, the analysis of the application of hidden classrooms in the art curriculum under current new media perspective still stays at theoretical level and the amount of data collected is far from sufficient. In terms of the current application of new media in art teaching, the application of new media may play a crucial role in future art teaching to promote individualized learning of students, develop students' innovation ability and cultivate students' ability to find and solve problems.

\section{ACKNOWLEDGMENT}

I would like to express my heartfelt thanks to my teacher, associate professor Zhang Tianzuo. He enlightens my ignorance, leads me gradually into good practices and supports me with his spirit all the times. I am also grateful to my parents and families for their support and care of my studying and living. You are always my spiritual pillar and the driving force of my progress.

This is another starting point of my life, which stretches endlessly ahead, I will go up and down to seek my heart's desire. I searched a large number of references for my paper, and I express my thanks to all the scholars quoted by me together here. Although this paper is guided by good teachers, defects may still exist due to my slow-witted and less advanced intelligence. Please correct any errors strictly.

\section{REFERENCES}

[1] Rudolf Arnheim. Art and Visual Perception [M]. Translated by Teng Shouyao, Zhu Jiangyuan. Chengdu: Sichuan People's Publishing Housing, 1998. (in Chinese) 
[2] Elloit W. Eisner. Development of Children's Perception and Vision [M]. Translated by Zhang Dan, Liu Haiying, Sun Hong, Ge Lingling. Changsha: Hunan Fine Arts Publishing Housing, 1993. (in Chinese)

[3] Rudolf Arnheim. Visual Thinking [M]. Translated by Teng Shouyao. Beijing: Commercial Press, 2005. (in Chinese)

[4] Art Curriculum Standard of Senior High School (Version 2017). Formulated by the Ministry of Education of the People's Republic of China, People's Education Press. (in Chinese)

[5] Interpretation of Art Curriculum Standard of Senior High School (Version 2017). Organized by Expert Working Committee of Elementary Education Textbooks, Ministry of Education, Compiled by Review Group of Art Curriculum Standard of Senior High School, Edited by Xi Chuanji, Yi Shaochun. Higher Education Press. (in Chinese)

[6] Compulsory Education Art Curriculum Standard (Version 2011). Formulated by the Ministry of Education of the People's Republic of China, Beijing Normal University Press. (in Chinese)

[7] Interpretation of Compulsory Education Art Curriculum Standard (Version 2011). Organized by Expert Working Committee of Elementary Education Textbooks, Ministry of Education. Beijing Normal University Press. (in Chinese)

[8] Will Gompertz. 150 Years of Modern Art [M]. Translated by Wang Shuo, Wang Tongle. Guangxi Normal University Press. (in Chinese)

[9] Edited by Wei Tianyu. Creative Art Education in the Era of Big Data - Collected Papers of the Fifth World Chinese Art Education Conference [C]. East China Normal University Press. (in Chinese)

[10] Edited by Yi Shaochun. Everybody's Opinion of the Core Literacy of Fine Arts. Hunan Fine Arts Publishing Housing. (in Chinese)

[11] Henry A. Giroux. Teachers Move Toward Critical Pedagogy as Intellectuals $[\mathrm{M}]$. Translated by Zhu Hongwen. Education Science Press. (in Chinese)

[12] Tom Anderson. Art for Life [M] Translated by Ma Jingru, Liu Nan, checked by Kuang Hong. Hunan Fine Arts Publishing Housing. (in Chinese)

[13] [US] Nicholas Mirzoeff. Translated by Ni Wei. Introduction to Visual Culture [M]. Jiangsu People's Publishing House.

[14] Research on Chinese Painting and Calligraphy Art beyond Tradition _ Tai Hai_ Neglect_ A Review of History of Humanities and Art \& Discussion on Chinese Painting and Calligraphy Research_Xia Dongrong. (in Chinese)

[15] Influence of New Media on Teenagers Growth and Educational Countermeasures_Zhang Junhui. (in Chinese)

[16] Opinion on Deepening the Educational System and Mechanism Reform. Opinion. Printed and published by General Office of the CPC Central Committee and General Office of the State Council. (in Chinese)

[17] Discussion on Visualization of Invisible Class for Moral Education in Art Schools. Classification No.: G641 Reference Code: A Article No.: 1674-9324 (2018) 31-0033-02 (in Chinese)

[18] Teacher Examination Research and Student Literacy Cultivation IIICultivation of Students' Ability of Solving Problems. Teacher's Journal. 2018 (08), 303. (in Chinese). 